\title{
BOBİ FRS AÇISINDAN MADDİ DURAN VARLIKLARIN MUHASEBELEŞTÍRILMESI ${ }^{*}$
}

\author{
Dr. Öğr. Üyesi Esin YELGEN ${ }^{a}$ \\ Prof. Dr. Süleyman UYAR ${ }^{\mathrm{b}}$
}

Teorik İnceleme

(Theoretical Research)

\author{
Muhasebe ve Vergi \\ Uygulamaları Dergisi \\ Nisan 2018; Özel Sayl: 98-109
}

\section{ÖZ}

Büyük ve Orta Boy İşletmeler için Finansal Raporlama Standardı (BOBİ FRS), bağımsız denetime tabi olup Türkiye Finansal Raporlama Standartlarını (TFRS) uygulamayan şirketlerin (MSUGT'i uygulayan işletmelerin) isteğe bağlı olarak uygulayacakları finansal raporlama çerçevesidir. BOBİ FRS seti, uluslararası muhasebe ve finansal raporlama uygulamalarıyla ve AB düzenlemeleriyle uyumlu olarak Kamu Gözetimi Muhasebe ve Denetim Standartları Kurumu (KGK) tarafindan hazırlanarak 29/07/2017 tarihli Resmi Gazete'de yayımlanarak yürürlüğe girmiştir. Bu tebliğe göre; şirketler 01/01/2018 tarihi ve sonrasında başlayan hesap dönemlerinde gerçeğe uygun, ihtiyaca uygun ve karşılaştırılabilir bilgi sağlamak amacıyla münferit ve konsolide finansal tablolarını BOBİ FRS'ye göre hazırlamaları gerekmektedir.

Yapılan bu çalışmada, ilk olarak BOBİ FRS'yi uygulayacak olan şirketlere ilişkin genel bir değerlendirme yapılmıştır. Ardından, şirketlerin bilançolarında önemli bir paya sahip olan maddi duran varlıkların (MDV) BOBİ FRS'ye göre muhasebeleştirme esasları ele alınmıştır. Bu kapsamda çalışmanın amacı, BOBİ FRS açısından maddi duran varlıklara ilişkin ilk kayda alınma, muhasebeleştirilme ve bu varlıklarla ilgili amortisman ve değer düşüklüğü konularını ayrıntılı şekilde açıklamaktır.

Anahtar Sözcükler: BOBİ FRS, Maddi Duran Varlıklar, Değerleme, Uygulama.

JEL Kodları: M41, M48, M49.

\section{RECOGNITION OF TANGIBLE ASSETS IN TERMS OF FINANCIAL REPORTING STANDARD FOR LARGE AND MEDIUM SIZED ENTERPRISES}

\section{ABSTRACT}

Financial Reporting Standards for Large and Medium Sized Enterprises (LME FRS) is the financial reporting framework that will be applied optionally by companies that are subject to independent audit and that do not apply Turkish Financial Reporting Standards (TFRS) (companies that implement General Communiqué on Accounting System Application

\footnotetext{
* Bu makale, 13-17 Aralık 2017 tarihinde Erzurum'da düzenlenen 4.Uluslararası Muhasebe ve Finans Araştırmaları Kongresinde sunulmuş olan özet bildirinin genişletilmiş tam metnidir.

${ }^{a}$ Ekonomi ve Finans Bölümü, İşletme Fakültesi, Alanya Alaaddin Keykubat Üniversitesi.

b İşletme Bölümü, İşletme Fakültesi, Alanya Alaaddin Keykubat Üniversitesi.
} 
(MSUGT)). LME FRS set, which was prepared by Public Oversight Accounting and Auditing Standards Authority (KGK) in compliance with international accounting and financial reporting applications and EU regulations, became effective after published in Official Gazette as of 29.07.2017. According to this communiqué; companies are required to prepare individual and consolidated financial statements in accordance with LME FRS in order to provide realistic, practical and comparable information during the fiscal periods starting on and after 01.01.2018.

In this study, a general evaluation was made firstly on the companies that will apply LME FRS. Then, the recognition principles for tangible assets according to LME FRS that have a significant share in the companies' balance sheet are addressed. Within this scope, the study aims to explain in detail the points about initial recognition, recognition and depreciation and impairment of tangible assets in terms of LME FRS.

Keywords: LME FRS, Tangible Assets, Valuation, Application.

JEL Codes: M41, M48, M49.

\section{GİRIŞ}

Türkiye'de muhasebe düzenlemeleri Maliye Bakanlığı ve Kamu Gözetimi, Muhasebe ve Denetim Standartları Kurumu (KGK) direktifleri çerçevesinde şekillenmektedir. Maliye Bakanlığı'nca 26.12.1992 tarihinde yayımlanarak 01.01.1994 tarihinden itibaren uygulanmaya başlanan Muhasebe Sistem Uygulama Genel Tebliği (MSUGT), Türkiye'deki muhasebe düzenlemeleri açısından temel teşkil etmektedir. Bununla birlikte, KGK tarafından yayımlanan Türkiye Finansal Raporlama Standartları (TFRS) seti, Kamu Yararını İlgilendiren Kuruluş (KAYİK) tanımı kapsamında yer alan şirketler tarafindan uygulanmaktadır.

KGK tarafından hazırlanan ve bağımsız denetime tabi olmakla birlikte KAYİK kapsamında olmayan şirketler tarafından isteğe bağlı olarak uygulanacak diğer bir set olan Büyük ve Orta Boy İşletmeler İçin Finansal Raporlama Standardı (BOBİ FRS) hakkında tebliğ 29/07/2017 tarihli Resmi Gazete'de yayımlanarak yürürlüğe girmiştir. Buna göre; bağımsız denetime tabi olup Türkiye Finansal Raporlama Standartları'nı (TFRS) uygulamayan şirketlerden (diğer bir ifade ile MSUGT uygulayan şirketlerin) bu standartları uygulamak isteyenler, 01/01/2018 tarihi ve sonrasında başlayan hesap dönemlerinde münferit ve konsolide finansal tablolarını BOBİ FRS'ye göre hazırlamaları gerekmektedir.

Tebliğde, BOBİ FRS'yi uygulayan şirketlerin iki yıl geçmedikçe isteğe bağlı olarak TFRS'yi uygulayamayacakları hüküm altına alınmıştır. Diğer taraftan isteğe bağl1 olarak TFRS'yi uygulayan şirketlerin BOBİ FRS'yi uygulayabilmeleri için en az iki yıl TFRS'yi uygulamış olmaları zorunludur.

Uluslararası muhasebe ve finansal raporlama uygulamalarıyla ve $A B$ düzenlemeleriyle uyumlu olan BOBİ FRS, işletmelerin genel olarak 
karşılaşabileceği tüm muhasebe işlemlerine ilişkin muhasebe esaslarını belirlemektedir. Bu kapsamda BOBİ FRS'nin amac1; gerçeğe uygun, finansal bilgi ihtiyacına uygun ve karşılaştırılabilir finansal tablolar düzenlemektir. Ayrıca BOBİ FRS; ortakların, yatırımcıların, kredi verenlerin, kamunun ve diğer tarafların bilgi ihtiyacını sağlayacak genel amaçlı finansal raporlama ilkelerini de karşılamaktadır.

BOBİ FRS uygulamasının başlanmasından sonra ortaya çıkabilecek problem, mevcut muhasebe kayıt sisteminde kullanılan Tek Düzen Hesap Planı'nda yer alan hesapların yeni sette belirtilen bazı hesapları karşılama noktasında yetersiz kalabilecek olmasıdır. Özellikle değer düşüklüğü ile ilgili muhasebeleştirmeler için bazı yeni hesapların tanımlanması gerekmektedir. Aksi takdirde, yeni sette önerilen hesap kalemleri yerine, BOBİ FRS'nin özünü tam olarak karşılayamayan ve mevcut kayıt sisteminde halihazırda kullanılan hesap kalemleri BOBİ FRS uygulayan işletmeler tarafında da zorunlu olarak kullanılmaya devam edilecektir.

Yapılan bu çalışmada, BOBİ FRS'yi uygulamak zorunda olan şirketlerin MDV'lerin ölçme ve muhasebeleştirme esaslarında ne gibi değişikliklerle karşı karşıya olduklarına ilişkin genel bir değerlendirme yapılmıştır. Ardından, BOBİ FRS açısından MDV'lerle ilgili olarak ilk kayda alınma, muhasebeleştirilme ve bu varlıklarla ilgili amortisman ve değer düşüklüğü konularına ilişkin çeşitli örnekler sunulmuştur.

\section{BOBİ FRS' DE MADDİ DURAN VARLIKLAR}

Maddi duran varlıklar, mal veya hizmet üretimi veya arzında kullanılan başkalarına kiraya verilmek veya idari amaçlar çerçevesinde kullanılmak üzere elde tutulan birden fazla dönemde kullanımı öngörülen fiziki varlıklardır.

Maddi duran varlıklar, ilk kayda alınmada maliyet bedeli ile ölçülmektedir. Maliyet bedeli; satınalma bedeli ve varlığın kullanıma hazır olması için yapılan giderlerden (nakliye, montaj, gümrük vergileri, noter ve mahkeme harcamaları vb.) oluşmaktadır.

Maddi duran varlığın maliyetinde arsa ve binalar birbirinden ayrılabilir varlıklardır. Bunlar birlikte edinilmiş olsa bile finansal tablolarda ayrı bir şekilde muhasebeleştirilmesi zorunlu kılınmıştır.

Varlığın ekonomik ömrünü uzatarak veya kapasitesini genişleterek ondan gelecekte elde edilecek faydayı artıran harcamalar söz konusu ise bu harcamalar defter değerine dahil edilirken, bu varlıklara ilişkin yıllık olağan bakım - onarım harcamaları gider olarak kabul edilmektedir. 
Vadeli olarak alınan maddi duran varlıklar, bir yıl ve daha kısa süre vade sözkonusu ise vade farkı ayrıştırılması yapılmadan peşin fiyatı (nakit tutarı) üzerinden ölçümü gerçekleştirilmektedir. Borçlanma maliyetleri ise oluştukları dönemde kar veya zarara yansıtılarak gösterilmektedir. Eğer ki bir maddi duran varlığın yapımı bir yıldan uzun sürerse bu kapsamda katlanılan borçlanma maliyetleri, varlık kullanıma hazır hale geldiği tarihe kadar varlığın maliyetine dahil edilmektedir.

MDV' lerin sonraki ölçümlerinde iki yöntem kullanılmaktadır. (1) Amortisman ve değer düşüklügü indirilmek suretiyle maliyet değeri, (2) Amortisman ve değer düşüklüğü indirilmek suretiyle yeniden değerleme tarihindeki gerçeğe uygun değer üzerinden sonraki ölçümün gerçekleştirilmesidir. Bir işletme politika olarak yeniden değerleme yöntemini benimsemiş ise değerlemenin yapılma sıklığı aynı olmalıdır. Bu bağlamda yeniden değerlemelerin sıklığı, yeniden değerleme konusu maddi duran varlık kalemlerinin gerçeğe uygun değerindeki değişmelere göre düzenlenmektedir. Yeniden değerleme, varlığın gerçeğe uygun değerinin defter değerinden önemli ölçüde farklılaşması durumunda yapılmaktadır. Bazı varlıklar yıllık olarak, önemli değişiklik göstermeyenler ise üç veya beş yılda bir yeniden değerleme yapılabilir. Değerleme işlemlerini kamu kurumlarınca yetkilendirilen kișiler yapabileceği gibi, gerekli mesleki yeterliliğe sahip MDV’lerin sınıf değeri hakkında güncel bilgisi bulunan kişilerde bu işlemleri gerçekleştirebilirler.

Değerleme işlemleri sırasında değer artışı ile karşılaşıldıysa özkaynaklar içinde yer alan yeniden değerleme yedeği hesabında ilgili tutar takip edilir. Daha önce kar veya zararda kaydedilen bir değer azalışı var ise ilk olarak bu azalış tersine çevrilmekte sonra kalan tutar sözkonusu ise değerleme yedeği hesabına aktarılmaktadır. Değerleme işlemleri sırasında değer azalışı ile karşılaşıldıysa bu durum kar veya zararda gösterilmektedir. Değer artışında kaydedilmiş bir fon bulunmakta ise öncelikle bu fon kullanılarak durum tersine çevrilmektedir. Kalan bir tutarın olması durumunda ise yine bu durum kar veya zararda gösterilmektedir. Bir maddi duran varlık finansal tablo dışı bırakıldığında bu varlığa ilişkin olarak yeniden değerleme yedeğinde yer alan birikmiş olan tutar "Geçmiş Yıllar Kârları/Zararları" kalemine aktarilır.

Amortisman işlemleri, MDV'lerde zorunlu bir uygulamadır. Bir varlığın amortismana tabi tutarının faydalı ömür süresince sistematik bir şekilde dağıtılması suretiyle gerçekleştirilmektedir. Varlık dönem içinde alındıysa ve kullanılmaya başlandıysa kıst amortisman uygulamasına tabi tutulmaktadır. Amortismana tabi tutar, varlığın maliyet bedelinden veya yeniden değerleme sonrası bulunmuş tutardan kalıntı değerinin indirilmesi suretiyle belirlenmektedir. Bir varlığın faydalı ömrü varlığı kullanan işletme 
tarafından tespit edilmektedir. Ancak amortisman uygulamasında bazı varlıkların önemli kabul edilen parçalarının ömrü varlıktan farklı ise parçaya uygun olarak ayrı bir şekilde amortismana tabi tutulması özellikli bir durum olarak kabul edilmektedir. İşletmeler, amortisman yöntemlerini seçerken gelecekteki ekonomik faydaların beklenen tüketim biçimini en çok yansıtan yöntem olmasına özen göstermelidirler. $\mathrm{Bu}$ yöntemler; doğrusal amortisman, azalan kalanlar üzerinden amortisman ve üretim miktarı yöntemleridir.

MDV'lerin geri kazanılabilir tutarından daha yüksek bir değerle finansal tablolarda yer almasını önlemek için değer düșüklüğü düzenlenmektedir. Geri kazanılabilir tutar, varlığın satış maliyetleri düşülmüş gerçeğe uygun değeri ile kullanım değerinden yüksek olanıdır. Varlıklar, geri kazanılabilir tutarından daha yüksek bir tutarla bilançoda izlenemez. Bir varlığın defter değerinin geri kazanılabilir tutarından büyük olması durumunda değer düşüklüğü zararı oluşur. Her raporlama dönemi sonunda varlığın değer düşüklüğüne uğradığına ilişkin bir göstergenin mevcut olup olmadığ 1 değerlendirilir. $\mathrm{Bu}$ tür bir göstergenin mevcut olması durumunda ilgili varlığın geri kazanılabilir tutarı belirlenir. Varlığın değer düşüklüğüne uğradığına ilişkin herhangi bir göstergenin bulunmadığı durumlarda geri kazanılabilir tutarın belirlenmesine gerek yoktur. Geri kazanılabilir tutar, her bir varlık için ayrı ayrı belirlenmektedir.

Satış maliyetleri düşülmüş gerçeğe uygun değer, bir varlığın, bilgili ve istekli taraflar arasında karşılıklı pazarlık ortamında piyasa şartları çerçevesindeki satış tutarından, elden çıkarma maliyetleri indirildikten sonra elde edilebilecek tutardır. Bireysel olarak değer düşüklüğü testine tâbi tutulan ve maliyet bedeliyle ölçülen varlıklara ilişkin değer düşüklüğü zararları kâr veya zarara yansıtılır. Ancak yeniden değerlenmiş tutarı üzerinden ölçülen MDV'lerde değer düşüklüğü zararları "Maddi Duran Varlıklar" bölümüne göre yeniden değerleme değer azalışı olarak dikkate alınır. Kâr veya zarara yansıtılan değer düşüklüğü zararları Kâr veya Zarar Tablosunda varlığın kullanıldığı işletme fonksiyonuna ilişkin giderlerin yansıtıldığı kalemde gösterilir. Örneğin, pazarlama bölümüyle ilgili olarak kullanılan varlığa ilişkin değer düşüklüğü zararı "Pazarlama Giderleri" kaleminde, üretim

Bölümüyle ilgili kullanılan varlıklara ilişkin değer düşüklüğü zararı ise "Satışların Maliyeti” kaleminde gösterilir. İptal edilecek değer düşüklüğü zararı; bireysel olarak değer düşüklüğü testine tabi tutulan ve maliyet bedeli ile ölçülen varlıklarda kâr veya zarara yansitılarak Kâr veya Zarar Tablosunun ilgili kaleminde gösterilirken, yeniden değerlenmiş tutarı üzerinden ölçülen MDV'lerde "Maddi Duran Varlıklar" bölümüne göre yeniden değerleme değer artışı olarak dikkate alınır. 
MDV'ler, elden çıkarıldığında veya varlıktan gelecekte herhangi bir ekonomik fayda beklenmediği zaman finansal tablo dişı bırakılmaktadır. MDV'lerin finansal tablo dışı bırakılmasından doğan kazanç ya da kayıp kâr veya zarara yansitilmaktadir.

\section{BOBİ FRS - TFRS VE VUK KAPSAMINDA MADDİ DURAN VARLIKLARDA UYGULAMA FARKLILIKLARI}

BOBİ FRS, sonraki ölçüm konusunda TFRS ile uyumlu iken, VUK'a göre MDV'ler maliyet bedeli ile değerlenmektedir. Borçlanma maliyetleri hususunda BOBİ FRS, TFRS ile uyumlu iken VUK'ta ise kredi faizleri kazanılma döneminin sonuna kadar maliyete eklenmektedir. Sonra istenirse gider olarak kaydedilir. Amortisman konularında BOBİ FRS, TFRS ile uyumlu iken VUK'ta amortisman uygulaması ihtiyari olup faydalı ömür maliye bakanlığı tarafından belirlenmekte ve amortismana tabi tutar varlığın defter değeri olmaktadır.

Vade farklarını uygulama noktasında ise BOBI FRS, TFRS'den ve VUK'tan farklıdır. BOBİ FRS'ye göre 1 yılın altında vade farkları varlığın maliyetine eklenip 1 yıldan uzun vadeli alınan varlıklarda, vade fark1 ayrıştırılarak peşin fiyat üzerinden ölçülmektedir. TFRS'de ise bütün vade farkları varlığın maliyetinden ayrıştırılmaktadır. VUK'ta ise vade farkları varlığın maliyetine dahil edilmektedir.

\section{BOBİ FRS' DE MADDİ DURAN VARLIKLARA ILISSTKIN ÖRNEKLER}

\section{1. İlk Alım}

İşletme, 01.12.2017 tarihinde 900.000 ₹ $+8 \%$ KDV ile bina satın almıştır. Bina bedelini bankadaki hesabından ödemiştir.

01.12 .2017

\begin{tabular}{lr}
\hline 252. BİNALAR & 900.000 \\
191. İNDİRILECEK KDV & 72.000
\end{tabular}

102. BANKALAR 972.000

Bina satın alınması

\subsection{Vade Farkları}

İşletme, 01.12.2017 tarihinde 900.000 ₹ $+8 \% \mathrm{KDV}$ ile bir bina satın almıştır. İşletme aldığı bu binanın KDV'sini ve 300.000 も’sini banka

Muhasebe ve Vergi Uygulamaları Dergisi 
aracılığıyla peşin, kalan 600.000 Ł’sini birer yıl vadeli olmak üzere iki eşit taksitte senet ile ödeyecektir. İşletmenin faaliyet gösterdiği piyasada faiz oran1 \% 20'dir.

BOBİ FRS' ye göre binanın bugünkü değeri aşağıdaki şekilde hesaplanmıştır:

Bugünkü Değer $=300.000+\frac{300.000}{(1+0.20)^{1}}+\frac{300.000}{(1+0.20)^{2}}$

Bugünkü Değer $=300.000+250.000+208.334=758.334$

Söz konusu fabrika binasının alış maliyeti 758.334 ₹ olup, ilk muhasebeleştirmede bu alış maliyeti ile gerçekleştirilecektir. Aradaki fark olan $(900.000-758.334=141.666$ Ł) tutarın "Ertelenmiş Giderler" olarak dikkate alınması gerekecektir. Bu tutar, dönemlere yayıldığı için faiz gideri olarak kayda alınması mümkün değildir. Dolayısı ile Borç Reeskontları hesabında gösterilmiştir. Dönem sonlarında ilgili reeskont tutarı finansman giderleri hesabına aktarılacaktır.

$\begin{array}{lr}\text { 252. BINALAR } & 758.334 \\ \text { 32X. BORÇ REESKONTLARI } & 50.000 \\ \text { 32X.01 Ertelenmiş Giderler } & \\ \text { 42X. BORÇ REESKONTLARI } & 91.666 \\ \text { 42X.01 Ertelenmiş Giderler } & \\ \text { 191. İNDİRILECEK KDV } & 72.000\end{array}$

102. BANKALAR

372.000

321. BORÇ SENETLERİ 300.000

421. BORÇ SENETLERİ 300.000

Binanın vadeli olarak alınması

\subsection{Borçlanma Maliyetleri}

İşletme, 10 ay inşası süren bir bina inşa etmiştir. Bina inşaatına ilişkin kredi faizleri dışında yapılan harcamaların toplamı 800.000 ₹’dir. Bu dönemde inşaatın finansmanı için temin edilen kredinin faizi 100.000 Ł' dir. Duran varlığın edinilmesine ilişkin katlanılan 100.000 も finansman gideri dönemin finansal tablolarına yansıtılmak üzere giderleştirilir.

Binanın inşası bir yıldan uzun olması durumunda yapılan harcamalar binanın maliyetine eklenmektedir. 


\begin{tabular}{|c|c|c|}
\hline 258. YAPILMAKTA OLAN YATIRIMLAR & 800.000 & \\
\hline 780. FINANSMAN GIDERLERİ & 100.000 & \\
\hline 320. SATICILAR & & 800.000 \\
\hline 102. BANKALAR & & 100.000 \\
\hline \multicolumn{3}{|l|}{ İnşaa maliyetlerinin kaydedilmesi } \\
\hline 252. BİNALAR & 800.000 & \\
\hline 258. YAPILMAKTA OLAN YATIRIMLAR & & 800.000 \\
\hline İnşaatın sona ermesi & & \\
\hline
\end{tabular}

\subsection{Sonraki Ölçüm}

Maliyet Modeli: $\mathrm{Bu}$ yöntemde, bir maddi duran varlık kalemi varlık olarak muhasebeleştirildikten sonra, finansal tablolarda, maliyetinden birikmiş amortisman ve varsa birikmiş değer düşüklüğü zararları indirildikten sonraki değeri ile gösterilmektedir.

MDV Bilanço Değeri = (Elde etme veya üretim maliyeti) -( B.Amortismanları + Değer düşüklüğü zararları)

Örnek: İşletme 01 Ocak 2017 tarihinde 900.000 Ł’ye bir bina satın almıştır. İşletme bina için 50 yıllık faydalı ömür belirlemiş ve normal amortisman yöntemini uygulamayı tercih etmiştir. 01.01.2018 tarihi itibari binanın defter değeri ve yevmiye kaydı ne olacaktır?

\subsubsection{7 itibariyle;}

2017 y1l1 amortisman tutar $1=18.000$ も

01.01.2018 tarihi itibari ile binanın net defter değeri $=900.000-18.000=$ 882.000 も 01.01.2018

257. BİRIKKMIŞ AMORTISMANLAR 18.000 252. BINALAR 18.000

Binanın defter değerinin düzeltilmesi I

\section{Yeniden Değerleme Modeli:}

İşletmeler maddi duran varlığı yeniden değerlemeye tabi tuttuklarında, yeniden değerleme tarihindeki birikmiş amortisman tutarını aşağıdaki yöntemlerden birine göre işleme tabi tutacaklardır: 
- Varlığın brüt defter değerindeki değişiklikle orantılı olarak düzeltilir ve böylece yeniden değerleme sonrasındaki varlığın defter değeri yeniden değerlenmiş tutarına eşit olur. Bu yöntem genellikle bir varlığın, itfa edilen yenileme maliyetinin bir endeks uygulanarak yeniden değerlendiği durumlarda kullanılır.

- Varlığın brüt defter değeri ile netleştirilir ve net tutar yeniden değerleme sonrasındaki değere getirilir. $\mathrm{Bu}$ yöntem genellikle binalar için kullanılır.

Örnek: 01.01.2017 tarihinde 900.000 も’ye alınan bir bina için işletme 50 y1l faydalı ömür üzerinden normal amortisman yöntemini uygulamaktadır. İşletme, 3 yıl sonra (01.01.2020) bu varlık için değerleme yaptırmış olup varlık değerinin \%10 oranında arttığı tespit edilmiştir.

1.y1l (31.12.2017) amortisman tutar1 $=18.000$ も

2.y1l (31.12.2018) amortisman tutar1 $=18.000$ も

3.y1l (31.12.2019) amortisman tutar1 $=18.000$ も

Binanın net defter değeri $=846.000$ も

Binanın defter değeri $=900.000 * 0.10=90.000$ も

Birikmiş amortisman tutarı $=54.000 * 0.10=5.400$ も

Değer artış1 $=90.000-5.400=84.600$ も

Binanın değerlemeden sonraki net defter değeri $=930.600$ も

01.01 .2020

252. BINALAR

90.000

257. BİRIKMIŞ AMORTİSMANLAR

522. MDV YENIDEN DEĞERLEME ARTIŞLARI

84.600

Yeniden değer artışı

Örnek: İşletme kayıtlı değeri 900.000 ₹ olan binası için bugüne kadar (31.12.2017) 360.000 も birikmiş amortisman ayrılmıştır. Bu varlık için 522. MDV YENIDEN DEĞERLEME ARTIŞLARI fonunda biriken tutar 200.000 ₹'dir. İşletme 01.01.2018 tarihinde binayı yeniden değerlemeye tabi tutmuştur. Değerleme sonucunda bu varlığın değerinin \%20 oranında azaldığı tespit edilmiştir.

\begin{tabular}{|l|l|l|l|}
\hline & $\begin{array}{l}\text { Değer } \\
\text { Düsüklüğü } \\
\text { Oranı }\end{array}$ & $\begin{array}{l}\text { Değer } \\
\text { Düşüklüğü }\end{array}$ & Gerçeğe Uygun Değer \\
\hline
\end{tabular}




\begin{tabular}{|l|l|l|l|l|}
\hline $\begin{array}{l}\text { Binanın Kayıtlı } \\
\text { Değeri }\end{array}$ & 900.000 & 0,20 & 180.000 & $900.000-180.000=720.000$ \\
\hline $\begin{array}{l}\text { Birikmiş } \\
\text { Amortismanlar }\end{array}$ & 360.000 & 0,20 & 72.000 & $360.000-72.000=288.000$ \\
\hline $\begin{array}{l}\text { Net Defter } \\
\text { Değeri }\end{array}$ & 540.000 & 0,20 & 108.000 & $540.000-108.000=432.000$ \\
\hline
\end{tabular}

01.01.2018

522. MDV YENIDEN DEĞERLEME ARTIŞLARI 108.000

257. BIRIKMIŞ AMORTISMANLAR 72.000

25X. MDV DEĞER DÜŞÜKLÜĞÜ KARŞILIKLARI 180.000

Değer düşüklüğü

\subsection{Amortisman Uygulamaları}

\section{Normal Amortisman Yöntemi:}

Örnek: İşletme yönetim faaliyetlerinde kullanılmak üzere 01 Ocak 2017'de 900.000 є’ye bir bina satın almıştır. İşletme bina için 50 yıllık faydalı ömür belirlemiş olup bu süre sonunda binanın kalıntı değerinin olmayacağ 1 varsayılmıştır. İşletme, normal amortisman yöntemini uygulamayı tercih etmiştir.

Amortisman Tutarı $=($ Maliyet değeri - Kalıntı değer $) /$ Tahmini yararlı ömür $=(900.000-0) / 50=18.000$ も

$$
\text { 31.12.2017 }
$$

770. GENEL YÖNETIM GIDERLERI

18.000

257. BİRIKMİŞ AMORTISMANLAR

18.000

2017 y1lı amortisman tutarı

$$
\text { I }
$$

Doğrusal amortisman yöntemi olarak da ifade edilen bu yönteme göre, varlığın kalıntı değeri değişmediği sürece yararlı ömrü boyunca ayrılan amortisman gideri eşit olmaktadır.

\section{Azalan Bakiyeler Yöntemi:}

Örnek: $\mathrm{Bu}$ yöntemde, amortisman gideri yararlı ömür (50 y1l) boyunca azalır. Bu yönteme göre yıllık amortisman payı şu şekilde hesaplanır:

Amortisman Tutarı $=$ Dönem başındaki defter değeri $\mathrm{x}$ (normal amortisman oran 1 x 2)

Muhasebe ve Vergi Uygulamaları Dergisi 


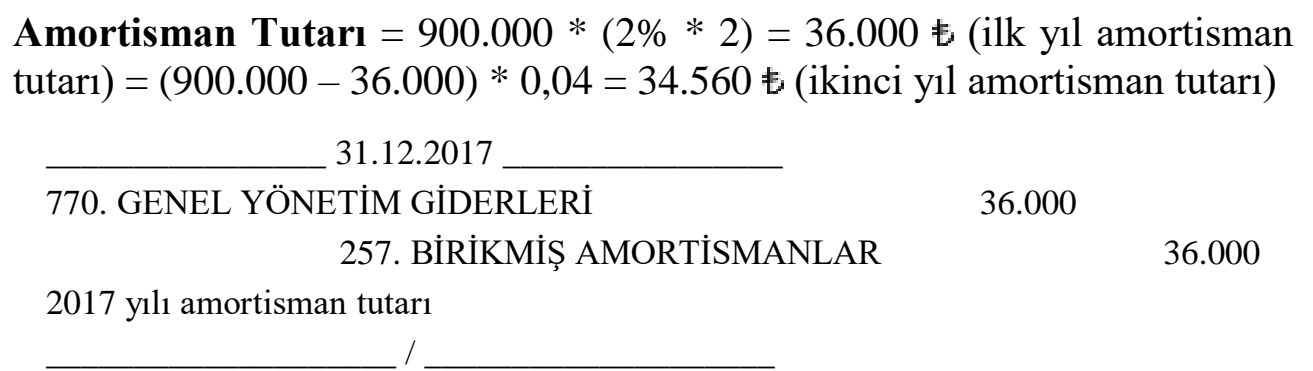

Üretim Miktarı Yöntemi: Bu yönteme göre duran varlığa ilişsin her yıl ayrılacak olan amortisman gideri, duran varlıktan beklenen kullanım yada üretim miktarına göre hesaplanmaktadır. Bu yönteme göre varlığa ilişkin yıllık amortisman tutarı aşağıdaki gibi hesaplanır. Bu yöntem, çalışmamızda uygulanmayacaktır.

Amortisman Oranı = $($ Maliyet değeri - Kalıntı değer $) /$ Varlığın tahmii üretim miktarı

Yıllık Amortisman Tutarı = Amortisman Oranı x Yıllık Üretim Miktarı

\subsection{Bilanço Dışı Bırakma}

Örnek: İşletme maliyet bedeli 900.000 ₹ ve o ana kadar birikmiş amortismanı 180.000 ₹ olan binasını 800.000 £' ye satmıştır. Bina bedeli işletmenin bankadaki hesabına yatırılmıştır. Buna göre aşağıdaki gibi bir muhasebe kaydı yapmalıdır:

\begin{tabular}{|c|c|c|}
\hline 102. BANKALAR & 800.000 & \\
\hline 257. BİRİKMİŞ AMORTISMANLAR & 180.000 & \\
\hline 252. BİNALAR & & 900.000 \\
\hline 649. DİĞER OLAĞAN GELİR VE KARLAR & & 80.000 \\
\hline Bina satışı & & \\
\hline
\end{tabular}

\section{SONUÇ}

Bağımsız denetime tabi olup Türkiye Finansal Raporlama Standartları'nı (TFRS) uygulamayan şirketler (diğer bir ifade ile MSUGT uygulayan şirketlerin), 01/01/2018 tarihi ve sonrasında başlayan hesap dönemlerinde münferit ve konsolide finansal tablolarını BOBİ FRS'ye göre hazırlamaları gerekmektedir. Uluslararası muhasebe ve finansal raporlama uygulamalarıyla ve $\mathrm{AB}$ düzenlemeleriyle uyumlu olan BOBİ FRS, işletmelerin genel olarak karşılaşabileceği tüm muhasebe işlemlerine ilişkin muhasebe esaslarını belirlemektedir. Bu kapsamda BOBİ FRS'nin amacı; 
gerçeğe uygun, finansal bilgi ihtiyacına uygun ve karşılaştırılabilir finansal tablolar düzenlemektir.

Özellikle sanayi işletmelerinde önemli bir yeri olan MDV'ler, bilançonun aktifinde ciddi bir paya sahiptir. MDV'lere ilişkin maliyetlerin, değerlemelerin, amorismanların doğru bir şekilde hesaplanması, fiyatlama kararları ve finansal tabloların doğru bir şekilde düzenlenmesi açısından son derece önem arz etmektedir. Bu çalışmanın amacı, BOBİ FRS 12. Bölüm Maddi Duran Varlıklara ilişkin maliyet unsurları ve maliyetin ölçümü, varlıkları değerleme yöntemleri olan maliyet yöntemi ve yeniden değerleme yöntemi, değerleme artışları veya azalışları ile amortisman kavramı ve amortisman yöntemlerine teorik bir bakıştır. Yapılan incelemeler sonucunda BOBİ FRS çerçevesinde MDV'lerin, sonraki ölçüm, borçlanma maliyetleri ve amortisman konularında TFRS ile uyumlu olduğu, vade farklarını uygulama noktasında TFRS'den farklı olduğu görülmüştür. BOBİ FRS'ye göre bir yıldan kısa vadeli alımlarda vade farkları varlığın maliyetine eklenirken, TFRS'ye göre vade farkları varlığın maliyetinden ayrıştırılmıştır. Bu kapsamda çalışmanın son bölümünde MDV'lerin, BOBİ FRS setinin 12. Bölümü kapsamında ilk kayda alınmaları, sonraki ölçümleri, vade farkları ve borçlanma maliyetleri konuları, değerleme ve amortisman uygulamaları hesaplamaları, hangi hesapların kullanıldığı, nasıl muhasebeleştirildiği ve değerlendiği örneklerle açıklanmıştır. Bundan sonraki çalışmalarda MDV'lerde muhasebe uygulamaları konusunda BOBI FRS, TMS/TFRS ile VUK arasında ortaya çıkacak muhasebeleştirme farklılıkları ele alınabilir. Sonuç olarak bu tür çalışmalar hem literatüre katkı yapacak hem de uygulamaya yol gösterecektir.

\section{KAYNAKÇA}

Kamu Gözetimi, Muhasebe ve Denetim Standartları Kurumu. (2017). Büyük ve Orta Boy Işsletmeler için Finansal Raporlama Standardt. Ankara.

Sağlam, N., Şengel, S., \& Öztürk, B. (2009). UFRS - UMS Uyumlu Türkiye Muhasebe Standartları Uygulaması. (3. Bask1). Ankara. 